\title{
ANALYSIS OF THE CAUSES OF INCOMPATIBILITY OF GEARBOX HOUSING CASTING
}

\author{
${ }^{1}$ Magdalena MAZUR, ${ }^{2}$ Karolina CZERWIŃSKA, ${ }^{3}$ Andrzej PACANA \\ ${ }^{1}$ Czestochowa University of Technology, Częstochowa, Poland, EU, magdalena.mazur@wz.pcz.pl \\ ${ }^{2}$ Rzeszow University of Technology, Rzeszow, Poland, EU, k.czerwinska@prz.edu.pl \\ ${ }^{3}$ Rzeszow University of Technology, Rzeszow, Poland, EU, app@prz.edu.pl
}

https://doi.org/10.37904/metal.2020.3656

\begin{abstract}
The purpose of the conducted tests was to apply an integrally configured method of quality control of the condition of modified helicopter gearbox housing castings. The use of this innovative method (consisting of the following techniques: Pareto-Lorenz diagram, Ishikawa diagram and 5WHY method?). would contribute to identifying the causes of non-compliant castings and, consequently, to eliminating non-compliant castings. As part of the analysis of the efficiency of checkpoints, a non-conformity test was carried out on the gearbox housing castings under analysis, including the identification of sensitive areas in terms of the number of defects. Transmission housing casts have become the subject of research due to significant problems with maintaining their desired level of quality after the introduced structural and technological changes. The proposed method has helped to identify the root cause of non-compliance. These were: inadequate flooding of moulds due to insufficient employee qualifications and inadequate human resources management. The study shows the advisability of using an integrated approach to finding the causes of quality problems on the example of a foundry. This was a new solution for the company, as no in-depth analyses of quality problems using a sequence of quality management techniques have been conducted so far. The improvement actions taken so far have been sufficient in a stabilised production process, but the modification of the process has shown the need to seek other more advanced techniques. This configured and integrated method was proposed and the expected results were achieved. The sequential method developed in the study is a universal way to prevent future non-compliance in this or other companies.
\end{abstract}

Keywords: mechanical engineering, quality engineering, Pareto-Lorenz diagram, Ishikawa diagram, 5WHY method

\section{INTRODUCTION}

The development and changes in the industrial economy make it necessary to ensure high quality products. Undertakings shall take steps to identify possible non-conformity of products and to prevent their occurrence in the future [1-3]. In the case of the manufacturing industry, casts that are found in every industry play an important role $[4,5]$. The most frequently produced castings in industry are aluminium castings. It is therefore important for the industry to provide castings that are free from defects. Sometimes this is problematic due to a large number of factors affecting them during production [6]. In order to check the quality of castings, the authors of many scientific studies indicate the possibility of using non-destructive testing (NDT), by means of which it is possible to identify possible inconsistencies without significant impact on its structural and surface properties $[7,8]$. However, sometimes the number of defects or discrepancies in castings is so large that it is difficult to identify the cause. The authors of the studies $[9,10]$ point out that the issue of tools supporting the decision-making process, which are available and on the basis of which data analyses are made, is not without significance. Comprehensive methods are constantly being sought to detect incompatibilities, but also to prevent them by detecting the sources of their origin or even looking for causes that cause problems within these sources. The methods enabling the implementation of the indicated activities are quality management 
methods, which, when skilfully applied, allow to increase the quality level of the offered products $[11,12]$. Literature studies on quality management often present the issues of quality analyses supported by the use of single quality management tools [13-15], or develop models for the optimisation of production processes [16-18]. However, there is still a lack of an integrally configured quality control method that has contributed to an in-depth causal analysis of production non-conformities - the identification of the root cause of nonconformity. Therefore, it is advisable to develop a sequence for the use of non-destructive testing (visual inspection), with quality management tools (the Pareto-Lorenz diagram correlated with the ABC method and brainstorming, the Ishikwa diagram, the $5 \mathrm{WHY}$ method and 5W1H [19]) in which the exit from one tool is an entry to the next.

\section{ANALYSIS}

\subsection{Aim, scope and subject matter}

The aim of the conducted tests was to diagnose in between operations, quality control of the condition of modified gearbox housing castings used in helicopters and to identify the causes of non-compliance in castings, in relation to which the application of appropriate preventive measures would contribute to the elimination of non-compliant castings. In connection with the increase of gearbox housing casting complaints by $4 \%$ as compared to the previous quarter, the survey was carried out on a batch of products made in the 2nd quarter of 2019. The scope of product inspection included the verification of casting area.

\subsubsection{Alloy characteristics}

The subject of the research was a gearbox foundry used in aviation. The object of research is cast by gravity from AlSi7Mg0.6 alloy. Chemical composition and mechnical properties of the alloy are presented in Table 1.

Table 1 The chemical composition and mechanical properties of the alloy (PN-EN 1706:2011)

\begin{tabular}{|c|c|c|c|c|c|c|c|c|c|c|c|}
\hline \multirow{3}{*}{$\begin{array}{l}\text { Chemical } \\
\text { composition }\end{array}$} & Element & $\mathrm{Fe}$ & Si & Mn & $\mathrm{Ti}$ & $\mathrm{Cu}$ & Mg & $\mathrm{Zn}$ & Oth & & Al \\
\hline & Min, [\%] & - & 6.50 & - & - & - & 0.45 & - & \multirow{2}{*}{\multicolumn{2}{|c|}{$\begin{array}{l}\text { each:0.03; } \\
\text { total: } 0.01\end{array}$}} & \multirow[t]{2}{*}{ emainder } \\
\hline & $\operatorname{Max},[\%]$ & 0.19 & 7.50 & 0.10 & 0.25 & 0.05 & 0.70 & 0.07 & & & \\
\hline \multirow{4}{*}{$\begin{array}{l}\text { Mechanical } \\
\text { properties }\end{array}$} & Property Name & \multicolumn{3}{|c|}{$\begin{array}{l}\text { Tensile strength } \\
\text { (Rm) }\end{array}$} & \multicolumn{2}{|c|}{$\begin{array}{l}\text { Yield strength } \\
\quad(R 0,2)\end{array}$} & \multicolumn{3}{|c|}{$\begin{array}{l}\text { Elongation at Break } \\
\text { (A) }\end{array}$} & \multicolumn{2}{|c|}{$\begin{array}{c}\text { Brinell } \\
\text { hardness }\end{array}$} \\
\hline & Min, [\%] & & 00 & \multirow{2}{*}{320} & 240 & \multirow{2}{*}{240} & & & \multirow{2}{*}{6} & 100 & \multirow{2}{*}{151} \\
\hline & Max, [\%] & & 50 & & 280 & & & & & 151 & \\
\hline & Unit of measure & & $\mathrm{mm}^{2}$ & $\mathrm{MPa}$ & $\mathrm{N} / \mathrm{mm}^{2}$ & $\mathrm{MPa}$ & & & $\%$ & $\mathrm{HB}$ & $\mathrm{HB}$ \\
\hline
\end{tabular}

The feature that distinguishes AlSi7Mg0. 6 alloy is its good weldability, exceptional corrosion resistance and very good machining properties $[9,20]$. Due to its properties, this alloy is used in aviation, automotive and architecture [21], mechanical engineering, food and chemical industry, as well as in shipbuilding, models and forms [22]. It may be also useful in biotechnology apparatus [23-25].

\section{METHODS OF THE TESTS}

Previously, the company did not apply in-depth analysis of the source causes of discrepancies in castings, however, due to the increase in complaints concerning gearbox castings and the increase in negative results of quality control, it was decided to take measures to increase the quality level. A team of experts has been set up, including the Head of the European Commission's Directorate-General for Health and Consumer Protection. The quality manager, foundry manager, technologist, constructor, and specialist in the field of 
quality assurance. complaints. In order to carry out a qualitative analysis of castings, studies were carried out, in which the integration of quality management tools was configured (Figure 1).

\begin{tabular}{|c|c|c|c|c|c|c|c|}
\hline $\begin{array}{l}\text { Characteriza } \\
\text { tion of the } \\
\text { problem }\end{array}$ & $\rightarrow$ & $\begin{array}{l}\text { Visualization } \\
\text { of obtained } \\
\text { results }\end{array}$ & $\rightarrow$ & $\begin{array}{l}\text { Pareto - Lorenz } \\
\text { diagram and } \\
\text { ABC method }\end{array}$ & $\rightarrow$ & $\begin{array}{l}\text { Brainstorming } \\
\text { and Ishikawa } \\
\text { diagram }\end{array}$ & $\begin{array}{l}\text { Method } \\
5 W H Y\end{array}$ \\
\hline
\end{tabular}

Figure 1 Applied sequence of methods

The first step of the analysis included characterisation of the problem (verification of defects of the raw surface, shape, continuity breaks and internal inconsistencies). In the areas of the products where discrepancies were detected during factory inspection (visual, ultrasonic and X-ray), metallographic surveys were performed. Samples for metallographic testing were cut out on a metallographic cutter and encapsulated in resin. Grinding and polishing of the samples was performed on the Saphir 530 and digested with $5 \%$ aqueous solution of HF acid. The microstructure was observed on the Zeiss Neophot 2 metallographic microscope. The next stage consisted in visualizing sensitive casting areas and indicating their type. The Pareto-Lorenzo analysis correlated with the $A B C$ method was performed to identify the most significant nonconformities in terms of their number and severity of effects. The brainstorming method was used by experts to identify potential causes of incompatibility in castings and their hierarchy. The potential causes are listed in the Ishikawa diagram. The 5 WHY method has been applied to the identified cause of non-compliance in order to identify its source.

\section{RESULTS}

The first step of the analysis was to identify the areas in the casting (Figure 2) where the most frequent irregularities occur and to determine the type of these defects.

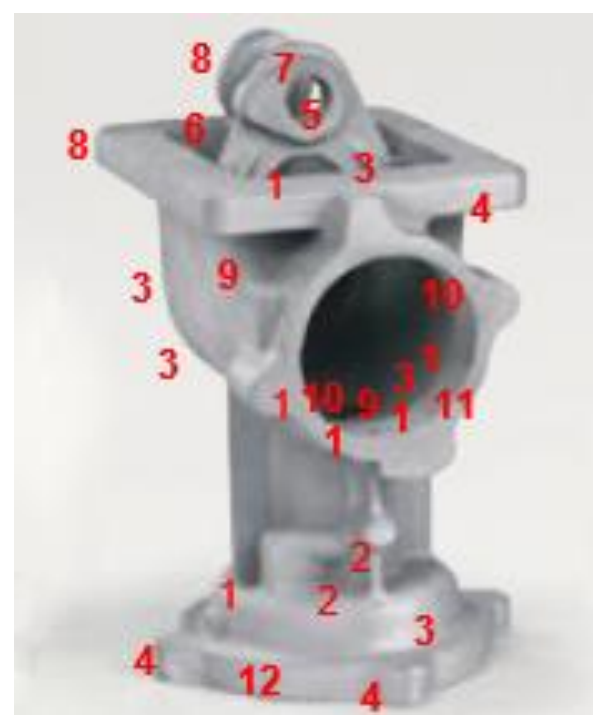

Figure 2 Model of casting gearbox with deforestation of areas where non-compliances marked as:

1 - systolic cavity are most common; 2 - misery; 3 - exfoliation; 4 - inclusions of foreign material; 5 - gas bladders; 6 - fastening; 7 - mismatch of felling thickness; 8 - mechanical damage; 9 - cold casting cracks;

10 - government; 11 - hot casting cracks; 12 - erroneous or illegible casting marking

Data concerning quality control during which the most defects are detected within a certain type of nonconformity and decisions concerning handling of nonconforming castings are presented in Table 2 (in the table the nonconformity markings as shown in Figure 2 were applied). The data confirm the relevance of the actions taken to identify the causes of non-compliance. 
Table 2 Percentage of decisions concerning gearbox castings where non-compliances are found

\begin{tabular}{|c|l|c|c|c|}
\hline \multirow{2}{*}{$\begin{array}{c}\text { Type of } \\
\text { defect }\end{array}$} & \multicolumn{1}{|c|}{ Quality control most often identifying non-compliance } & \multicolumn{3}{|c|}{ Decision } \\
\cline { 3 - 5 } & \multicolumn{1}{|c|}{ Utilization } & Repair & Admission \\
\hline 1. & $\begin{array}{l}\text { Inter-operative control (ultrasonic and radiological defectoscopy, } \\
\text { macroscopic examination) }\end{array}$ & $88 \%$ & $7 \%$ & $5 \%$ \\
\hline 2. & Inter-operative control (visual) & $66 \%$ & $17 \%$ & $17 \%$ \\
\hline 3. & Inter-operative control (visual) & $31 \%$ & $53 \%$ & $16 \%$ \\
\hline 4. & $\begin{array}{l}\text { Inter-operative control (visual, ultrasonic defectoscopy, } \\
\text { radiological defectoscopy, light microscopic examination) }\end{array}$ & $64 \%$ & $29 \%$ & $7 \%$ \\
\hline 5. & $\begin{array}{l}\text { Intraoperative control (ultrasonic and radiological defectoscopy, } \\
\text { penetration tests, microscopic - light tests) }\end{array}$ & $71 \%$ & $11 \%$ & $18 \%$ \\
\hline 6. & Pre-check (visual, X-ray method) & $63 \%$ & $15 \%$ & $23 \%$ \\
\hline 7. & Inter-operative control (using an electronic calliper) & $8 \%$ & $81 \%$ & $11 \%$ \\
\hline 8. & Pre- and post-operative (visual) checks & $86 \%$ & $8 \%$ & $6 \%$ \\
\hline 9. & $\begin{array}{l}\text { Inter-operational control (ultrasonic and radiological defectoscopic } \\
\text { examination, microscopic - light examination) }\end{array}$ & $87 \%$ & $15 \%$ & $2 \%$ \\
\hline 10. & $\begin{array}{l}\text { Preliminary inspection (ultrasonic and radiological defectoscopy, } \\
\text { macroscopic examination) }\end{array}$ & $79 \%$ & $15 \%$ & $6 \%$ \\
\hline 11. & $\begin{array}{l}\text { Inter-operational control (ultrasonic and radiological defectoscopic } \\
\text { examination, microscopic - light examination) }\end{array}$ & $85 \%$ & $9 \%$ & $6 \%$ \\
\hline Pre- and post-operative (visual) checks & $0 \%$ & $100 \%$ & $0 \%$ \\
\hline
\end{tabular}

\section{ANALYSIS}

The instrument proposed by the working team to carry out further analysis of castings'; inconsistencies was the Pareto-Lorenz analysis correlated with the ABC method. The aim of the action taken was to identify the most significant noncompliances (Figure 3). Markings as indicated in Figure 2.

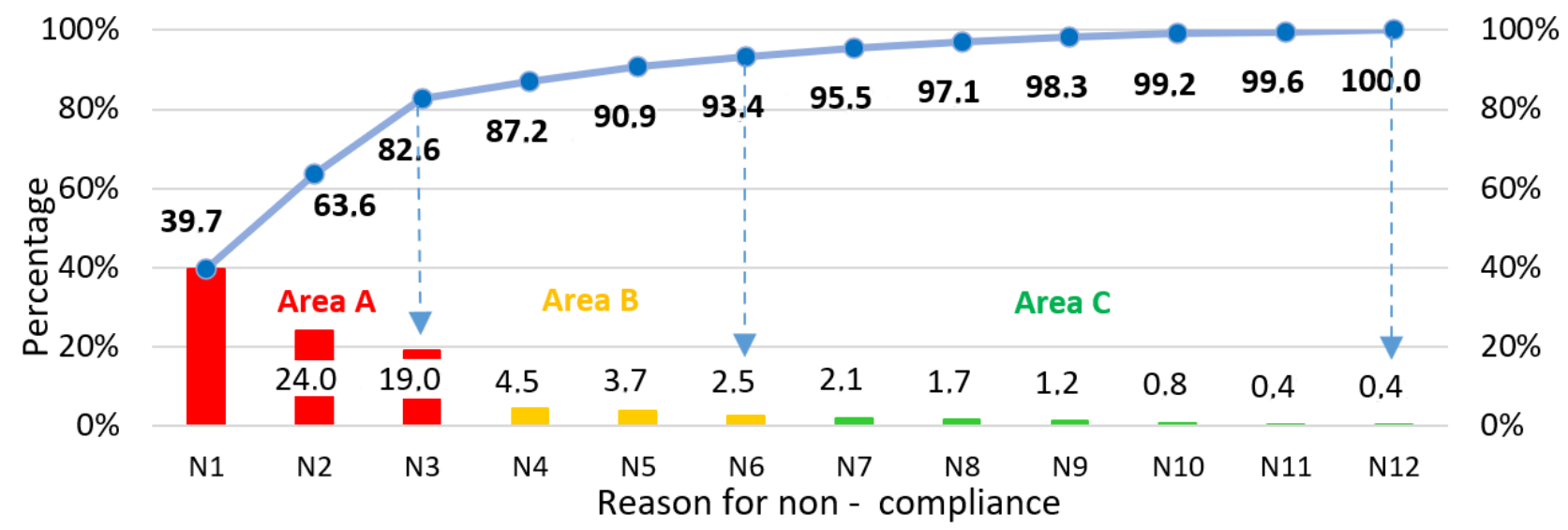

Figure 3 Pareto Lorenzo diagram with $A B C$ method for gearbox casting incompatibility

The analysis of casting batches showed that the systolic cavities $(39.7 \%)$, underpressure $(24.0 \%)$ and peeling $(19.0 \%)$ are the most serious inconsistencies. In accordance with the ABC method, area A - to which the claimed non-conformities are qualified - is defined as critical. Figure $\mathbf{4}$ shows the most common forms of incompatibility - the systolic cavity. In the tested batch of products, the shrinkage cavities are in the form of a jagged discontinuity often surrounded by porosity, rusticity. 

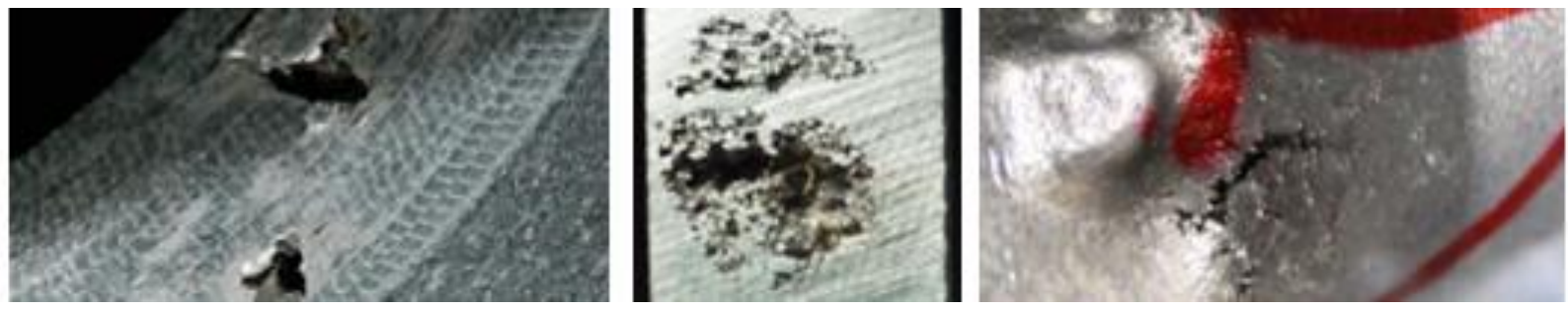

Figure 4 Result of the discontinuity - systolic cavity test

The potential causes of unworthiness identified during the brainstorming session have been arranged in the Ishikawa diagram showing mutual links between the causes. Due to the volume limitations, the study includes the part of the Ishikawa diagram containing the key cause of non-compliance (Figure 5). It was found that the key reason for the occurrence of shrinkage cavities was too low an alloy temperature during pouring of the moulds. As a further analysis of the qualitative problem, the 5WHY method was developed (Figure 6).

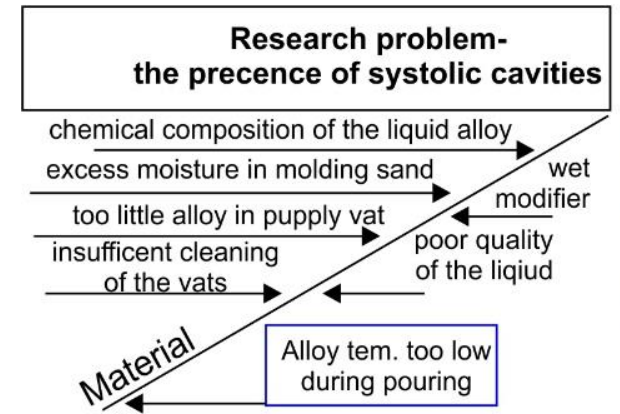

Figure 5 Fragment of the Ishikawa diagram showing the causes of the systolic cavity in the „material” category

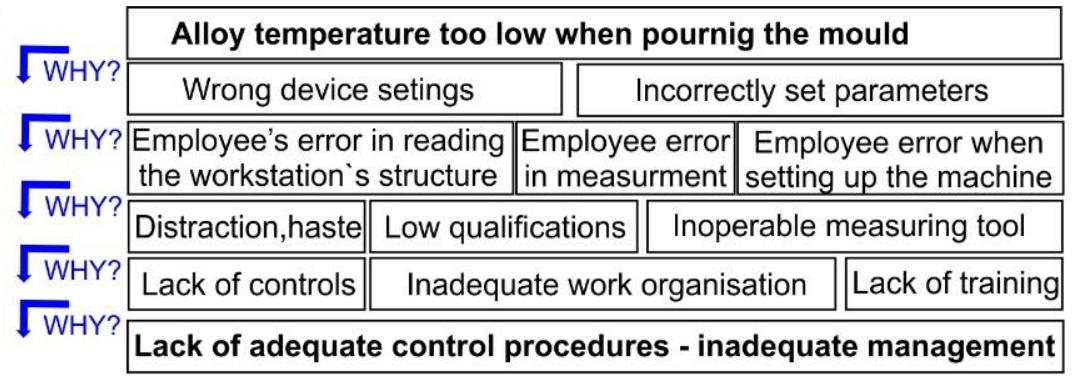

Figure 6 Course of the 5Why method for incompatibility concerning too low an alloy temperature during mould pouring

The analysis (Figure 6) shows that the key reason for flooding the mould with an alloy with too low a temperature was the lack of training of the newly employed worker. There was an employee at the workstation who incorrectly read the parameters of the instruction. The combination of too little experience and lack of training was the main reason for the discrepancies.

\section{CONCLUSION}

The proposal of detailed analysis of nonconformities, presented in the study, concerning the identification of areas where defects are most frequently located and the identification of the causes of the presence of defects in castings, combined with the application of configured integration of quality management tools, contributes to their elimination and the implementation of effective measures to prevent the occurrence of nonconformities in castings. The key reason for the occurrence of the most significant nonconformity in the gearbox housing casting (presence of shrinkage cavities) was the inappropriate pouring temperature of the casting mould due to the lack of training of the newly employed employee, which resulted from inadequate human resources management in the company. Further research will be related to the implication of the proposed sequence of analysis of casting's nonconformity, which is an effective way of solving quality problems in the production of other products offered by the company. The presented method of analysis of types and weights of nonconformity, including the importance of the control points present in the company, in combination with the quality management methods, is largely complementary. The proposed sequential combination may be a component of methods supporting quality management processes. 


\section{REFERENCES}

[1] PACANA A., CZERWIŃSKA K., BEDNAROWA L., Discrepancies analysis of casts of diesel engine piston, Metalurgija. 2018, vol.57, pp. 324-326.

[2] PACANA A., CZERWIŃSKA K., BEDNAROWA L., Comprehensive improvement of the surface quality of the diesel engine piston, Metalurgija. 2019, vol.58, pp. 329-332.

[3] PACANA, A., CZERWIŃSKA, K. Analysis of causes of control panel inconsistencies in the gravitational casting process by means of quality management instruments, Production Engineering Archives. 2019, vol.25, pp.12-16.

[4] KNOP, K., OLEJARZ, E., ULEWICZ, R. Evaluating and Improving the Effectiveness of Visual Inspection of Products from the Automotive Industry, Advances In Manufacturing II - Quality engineering and management. 2019, vol. 3, pp. 231-243.

[5] MERY D. Automated radioscopic testing of aluminum die castings, Materials Evaluation. 2006, vol. 64, pp. 135143.

[6] ŠVECOVÁ, I., TILLOVÁ, E., KUCHARIKOVÁ, L. Improving the quality of Al-Si castings by using ceramic filters, Production Engineering Archives. 2020, vol. 26, pp.19-24.

[7] BUSCHKE P., SCHAPPACHER W., Trends in the automotive industry steer new NDT applications, Insight. 2006, vol.48, pp. 532-536.

[8] INGALDI, M., DZIUBA, S.T., CIERNIAK-EMERYCH, A. Analysis of problems during implementation of Lean Manufacturing elements, MATEC Web of Conferences. 2018, vol. 183, art. 01004.

[9] BRIS R., Cost oriented statistical decision problem in acceptance sampling and quality control. In Applied Mathematics In Engineering And Reliability, CRC Press, 2016, pp. 19-26.

[10] SKOTNICKA-ZASADZIEŃ B., WOLNIAK R., ZASADZIEŃ M., Use of quality engineering tools and methods for the analysis of production processes - case study, In Proc. of $2^{\text {nd }}$ Int. Conf. on Economic and Business Management (FEBM 2017), 2017, vol. 33, pp. 240-245.

[11] LANGABEER JR. Performance management methods and tools. In Performance Improvement in Hospitals and Health Systems: Managing Analytics and Quality in Healthcare, $2^{\text {nd }}$ ed., CRC Press, 2018, pp. 43-61.

[12] ULEWICZ, R. Practical application of quality tools in the cast iron foundry, Manufacturing Technology. 2014, vol.14, pp. 104-111.

[13] NOWICKA-SKOWRON, M., ULEWICZ, R. Quality management in logistics processes in metal branch. In METAL 2015: 24 ${ }^{\text {th }}$ Int. Conf. on Metallurgy and Materials. Ostrava, TANGER, 2015, pp. 1707-1712.

[14] TRAN, T., LUU-NHAN, K., GHABOUR, R., DAROCZI, M. The use of Lean Six-Sigma tools in the improvement of a manufacturing company - case study, Production Engineering Archives. 2020, vol.26, pp. 30-35.

[15] SUAREZ-BARRAZA FM. and RODRIGUEZ-GONZALEZ FG. Cornerstone root causes through the analysis of the Ishikawa diagram, is it possible to find them? A first research approach, International Journal of Quality and Service Sciences. 2019, vol.11, pp. 302-316.

[16] AZID IA., ANI MNC., HAMID SAA., KAMARUDDIN S. Solving production bottleneck through time study analysis and quality tools integration, International Journal of Industrial Engineering. 2020, vol. 27, pp. 13-27.

[17] KUMAR SS., KUMAR MP. Cycle time reduction of a truck body assembly in an automobile industry by lean principles, In Int. Conf. on Advances in Manufacturing and Materials Engineering (ICAMME 2014). 2014, vol. 5, pp. 1853-1862.

[18] ULEWICZ, R., SELEJDAK, J., BORKOWSKI, S., JAGUSIAK-KOCIK, M. Process management in the cast iron foundry. In 22nd Int. Conf. on Metallurgy and Materials METAL 2013. Ostrava: TANGER, 2013, pp. 1926-1931.

[19] KNOP, K., MIELCZAREK, K. Using $5 \mathrm{~W}-1 \mathrm{H}$ and $4 \mathrm{M}$ methods to analyse and solve the problem with the visual inspection process - Case study. MATEC Web of Conferences. 2018, vol. 183, art. 03006.

[20] BIROL, Y. Effect of solution heat treatment on the age hardening capacity of dendritic and globular AISi7Mg0.6 alloys.s International Journal of Materials Research. 2010, vol. 101, pp. 439-444.

[21] HURTALOVÁ L., BELAN J., TILLOVÁ E., CHALUPOVÁ M. Changes in Structural Characteristics of Hypoeutectic Al-Si Cast Alloy after Age Hardening. Materials Science. 2012, vol.18, pp. 228-233. 
[22] CAVALIERE P., CERRI E., LEO P. Effect of heat treatment on mechanical properties and fracture behaviour of a thixocast A356 aluminum alloy. Journal of Material Science. 2004, vol.39, pp. 1653-1658.

[23] SKRZYPCZAK-PIETRASZEK, E., PISKA, K., PIETRASZEK, J. Enhanced production of the pharmaceutically important polyphenolic compounds in Vitex agnus castus L. shoot cultures by precursor feeding strategy. Engineering in Life Sciences. 2018, vol. 18, pp. 287-297.

[24] SKRZYPCZAK-PIETRASZEK, E., REISS, K., ZMUDZKI, P., PIETRASZEK, J. Enhanced accumulation of harpagide and 8-O-acetyl-harpagide in Melittis melissophyllum L. agitated shoot cultures analyzed by UPLCMS/MS. PLOS One. 2018, vol. 13, art. e0202556.

[25] SKRZYPCZAK-PIETRASZEK, E., URBANSKA, A., ZMUDZKI, P., PIETRASZEK, J. Elicitation with methyl jasmonate combined with cultivation in the Plantform ${ }^{\mathrm{TM}}$ temporary immersion bioreactor highly increases the accumulation of selected centellosides and phenolics in Centella asiatica (L.) Urban shoot culture. Engineering in Life Sciences. 2019, vol. 19, pp.931-943. 